\title{
DA OBSOLETA CARÊNCIA DE DOMINAÇÃO A UM NOVO PRINCÍPIO DE REALIDADE SEGUNDO MARCUSE
}

\author{
Manoel Dionizio Neto ${ }^{1}$
}

\begin{abstract}
Resumo:
Tendo como referência fundamental Eros e Civilização, de Herbert Marcuse, busca-se a compreensão do exposto por Sigmund Freud a respeito das condições em que se deu a formação da cultura e o desenvolvimento da civilização a partir da interpretação marcusiana do pensamento de Freud. Valendo-se então do exposto por Marcuse em sua obra, procura-se a fundamentação para o que fora exposto sobre a substituição do Princípio de Prazer pelo Princípio de Realidade que, com o avanço da civilização, deu lugar ao Princípio de Desempenho. Considera-se para tanto a significação das camadas mentais, identificadas por Freud como Id, Ego e Superego, para a compreensão da repressão dos instintos vitais que tornou possível o Princípio de Realidade, assim como se fez possível o Princípio de Desempenho graças à mais-repressão segundo a interpretação de Marcuse. Partindose do entendimento de que a dominação se fez necessária para que houvesse a efetivação da repressão sexual entre os primórdios da humanidade, vale então refletir sobre a possibilidade de um novo Princípio de Realidade, quando não se tem mais a carência dessa dominação, considerando-se para isto o estágio de desenvolvimento da civilização em nossos dias.
\end{abstract}

Palavras-chave: Marcuse; Freud; Princípio de Realidade; Princípio do Prazer; Dominação.

\section{FROM THE OBSOLETE LACK OF DOMINATION TO A NEW REALITY PRINCIPLE ACCORDING TO MARCUSE}

\begin{abstract}
:
The fundamental reference work Eros and Civilization, by Herbert Marcuse, is taken to understand Sigmund Freud's comprehension about the conditions for cultural formation and for development of civilization, from Marcuse's interpretation on Freud's thoughts. Based on Marcuse's book, we seek the foundation for replacement of the Pleasure Principle by the Reality Principle, which, as civilization advances, gave way to the Performance Principle. Therefore, we consider the significance of the mental layers, identified by Freud as Id, Ego and Superego, for understanding the repression of vital instincts that made possible the Reality Principle, as well as made possible the Performance Principle, thanks to the surplus repression, according to Marcuse's interpretation. From the understanding that domination was necessary for sexual repression in the beginnings of humanity, it is worth reflecting on the possibility of a new Reality Principle, when there is no longer need of this domination, considering the stage of development of civilization in the present day.
\end{abstract}

Keywords: Marcuse; Freud; Reality Principle; Pleasure Principle; Domination.

1 Manoel Dionizio Neto - Graduado em Filosofia pela UFPE (Licenciatura e Bacharelado), Mestrado em Filosofia pela UFPB e Doutorado em Educação pela UFSCar, é Professor Associado IV na Unidade Acadêmica de Ciências Sociais do Centro de Formação de Professores da UFCG (Universidade Federal de Capina Grande). Atua como professor de Filosofia e tem como referência o pensamento de Rousseau e a Teoria Crítica, com ênfase em Marcuse, Adorno e Horkheimer, bem como o existencialismo e a fenomenologia, ressaltando-se Sartre e Merleau-Ponty. E-mail: dionizioneto@uol.com.br. 


\section{Introdução}

No "Prefácio" a Eros e civilização, em 1966, Herbert Marcuse manifesta sua inquietação em relação às mudanças dos costumes requeridas por Wilhelm Reich em sua obra Revolução sexual. Mesmo não se tratando da efetivação desta revolução, vislumbrava-se muito com essas mudanças as projeções do próprio Marcuse que via a possibilidade do ser humano lidar de forma diferenciada com a gratificação do prazer inviabilizada pela histórica repressão sexual. Mas, ao prefaciar sua obra, Marcuse demonstra sua decepção: os avanços da sociedade industrial não conduziram o progresso para a reversão esperada na década de 1950, assim como não rompera a união entre produção e destruição nem a relação entre liberdade e repressão. Conforme as suas próprias palavras, não levou o homem "a aprender a gaya sciencia de como usar a riqueza social para moldar o mundo do homem de acordo com os seus Instintos Vitais, na luta combinada contra os provisores da Morte" (MARCUSE, 1981, p. 13).

Partindo desse desencanto com o otimismo com que escrevera a sua obra, refletimos sobre a carência de dominação que, segundo Marcuse, já se encontrava obsoleta naquela época. Perguntamos, então, por essa "carência de dominação" vista como obsoleta, bem como sobre as condições para um novo princípio de realidade. Hoje, depois de todas as mudanças dos costumes ocorridas a partir dos anos de 1960, seria possível retomarmos àquele otimismo, mesmo tomando como base outros referenciais, depois da certificação de que os avanços da ciência e da tecnologia não contribuíram para o que fora esperado?

Fala-se muito numa pós-modernidade ou numa modernidade líquida, como o faz Zygmunt Bauman, para quem estamos em meio a fluidez de um mundo, onde tudo pode acontecer sem que se possa contar com a estabilidade de alguma coisa. Até é possível falar numa pós-orgia, como o faz Jean Baudrillard. E não podemos esquecer das diferentes possibilidades de amar referidas por Carl R. Rogers. Podemos então pensar numa nova civilização conforme a projeção de Alvin Toffler? Marcuse lembra do preço pago pelo povo para a aquisição da liberdade. Até se pode comparar ao preço referido por Rousseau ao falar da troca de uma felicidade real por uma tranquilidade imaginária. Trata-se, pois, segundo Marcuse, de considerar a dependência da sociedade afluente de uma ininterrupta produção e do consumo do supérfluo. É esta mesma sociedade, segundo ele, que depende igualmente dos novos inventos, acompanhados do "obsoletismo planejado e dos meios de destruição", quando se inventa tudo com vistas à curta duração que faz da produção coisa descartável. A essa

\begin{tabular}{|c|c|c|c|c|}
\cline { 2 - 4 } & Ano 8 & n. 14 & Janeiro - Julho 2019 & p. $70-90$ \\
\hline
\end{tabular}


sociedade, os indivíduos são obrigados a se adaptarem. Como então falar da superação do princípio de desempenho por um novo princípio de realidade?

Marcuse lembra também que não se trata de falar de libertação para quem é livre, assim como se deve falar de excessiva repressão sexual, quando homens e mulheres praticam sexo como nunca o fizeram. De fato: comparemos as condições em que se praticam sexo hoje com as que estavam postas na década de 1960. E o que dizer do que ocorriam nas décadas anteriores? Hoje, é cada vez mais comum a vida marital dos namorados, no âmbito da heterossexualidade ou não. Se ainda se defende a virgindade da mulher, ou que ela só pratique sexo depois do casamento, a virgindade não é mais obrigatória. $\mathrm{O}$ mesmo se pode dizer em termos de vestuário: homens e mulheres se vestem como querem, com o mínimo de roupa possível, sem obstáculos às transparências ou sensualidade no modo de vestir. Seria, então, que já contamos com o novo princípio de realidade referido por Marcuse?

A resposta à pergunta acima nos remete à significação da dominação em nossos dias, e não podemos refletir sobre um novo princípio de realidade sem trazer para a reflexão o significado da carência de dominação. Por isso retomamos ao sentido da repressão como condição para a civilização, conforme o entendimento de Freud, e à passagem da repressão a uma mais-repressão como passagem ao princípio de desempenho.

Da repressão como condição à civilização à mais-repressão como condição ao princípio de desempenho.

\section{Da repressão como condição à civilização à mais-repressão}

Herbert Marcuse volta-se para o significado da repressão, quando invoca o pensamento de Freud para falar do ser humano como um ser historicamente reprimido. Pois ele chama a atenção para a conclusão a que chegara Freud ao falar da história do homem que, segundo ele, confunde-se com a história de sua repressão. Neste sentido, pode-se falar de uma coação da cultura, tanto em relação à existência social como em relação à existência biológica do ser humano. Pois, graças a essa coação, o progresso se faz possível, tornando-se assim viável a civilização. Isto é o mesmo que falar da incompatibilidade entre a liberação dos instintos básicos do homem e as possíveis associações humanas e a sua durabilidade. Ou seja, não se poderia falar de relações duradoras dos seres humanos, se eles se estivessem em plena liberdade sexual. A libertação dos instintos básicos, necessária para as livres relações sexuais, destruiria tudo que dissesse respeito à união, assim como destruiria tudo que pudesse fazer a comunhão

\begin{tabular}{|l|c|c|c|c|}
\cline { 2 - 5 } & Ano 8 & n. 14 & Janeiro - Julho 2019 & p. $70-90$ \\
\hline
\end{tabular}


deles. Ou seja, como diz Marcuse (1981, p. 33): “O Eros incontrolado é tão funesto quanto a sua réplica fatal, o instinto de morte". Por que, então, falar desse caráter destruidor, que pode ser visto no próprio Eros, se deixá-lo fora de controle? Segundo Marcuse, para Freud, ocorreria o seguinte: "Sua força destrutiva deriva do fato deles lutarem por uma gratificação que a cultura não pode consentir: a gratificação como tal e como um fim em si mesma, a qualquer momento" (Ibidem). Isto significa que Eros deve ser desviado dos seus objetivos, assim como se faz necessário inibi-lo em relação aos seus anseios. Pois, afinal, é preciso ter sempre em vista à civilização como algo imprescindível ao homem. E esta civilização não seria possível sem a repressão desses instintos básicos, ou seja, sem que Eros fosse reprimido: "A civilização começa quando o objetivo primário - isto é, a satisfação integral de necessidades - é abandonado" (Ibidem).

Fica assim claro que, para Freud, não seria possível a civilização sem a repressão. E não era disto que falava Thomaz Hobbes quando fez referência a um contrato entre os homens que garantisse a continuidade da vida e, portanto, da sociedade humana devidamente organizada, submetendo-se todos à vontade de um só? Afinal se tratava da eleição de um príncipe que pudesse garantir a segurança de todos. Mas, a que preço? O preço não seria assim a repressão necessária, para que todos se submetessem às determinações de um senhor? Assim, diferentes teorias, e mais ainda as intervenções das diferentes religiões ou dos diferentes modos de governo, têm apontado para a necessidade de controle do comportamento humano, evitando-se a manifestação da sexualidade como modo de aprisionamento de Eros, isto é, desses instintos básicos a que se reporta Marcuse ao trazer o pensamento de Freud para a sua interpretação. Falar desse aprisionamento dos instintos básicos é, na verdade, falar da repressão, e esta repressão, mesmo que inicialmente possa ser manifesta com seu caráter político, acaba esbarrando na repressão sexual propriamente dita. Mas, o que isto significa? O que nos permite falar dessa repressão sexual? Creio que Marilena Chaui (1984, p. 77) sintetiza muito bem o que se pode entender por isso:

De modo geral, entende-se por repressão sexual o sistema de normas, regras, leis e valores explícitos que uma sociedade estabelece no tocante a permissões e proibições nas práticas sexuais genitais (mesmo porque um dos aspectos profundos da repressão está justamente em não admitir a sexualidade infantil e não genital). Essas regras, normas, leis e valores são definidos explicitamente pela religião, pela moral, pelo direito e, no caso de nossa sociedade, pela ciência também.

\begin{tabular}{|c|c|c|c|c|}
\cline { 2 - 4 } & Ano 8 & n. 14 & Janeiro - Julho 2019 & p. $70-90$ \\
\hline
\end{tabular}


Como se faz, na prática, a aplicação desse sistema de normas, regras, leis e valores? Muitas vezes nos modos mais sutis pelos quais operam as instituições, no âmbito religioso e político, mas também em nome da ciência. E quando nos voltamos para o pensamento de Freud para compreender relação que, segundo ele, se dá necessariamente entre repressão e o progresso da civilização, precisamos considerar o que poderia ocorrer se os instintos básicos fossem completamente liberados. Pense-se naquela criança que tudo quer, e que, se ficar completamente livre para fazer o que quiser, não consciente do que possa acontecer posteriormente, destrua o que lhe for acessível, movida pela simples curiosidade ou o desejo de experienciar aquele momento numa relação específica com certos objetos desejados. Ressaltese aqui a não-consciência dos seus atos, isto é, não ter consciência do significado das suas ações. Essa criança não contribuiria de forma alguma para a permanência de um mundo já estabelecido, e muito menos para o progresso do que já estivesse devidamente produzido e, portanto, organizado. É nestes termos que pensamos o entendimento de Freud ao considerar a necessidade da repressão, como controle do egoísmo humano, pois, impulsionado por este, pensando somente na satisfação dos seus desejos, o homem destrói sem jamais contribuir para a estabilidade e muito menos para o progresso. É o que poderia ocorrer, por esse entendimento, se os homens se deixassem levar pelos seus desejos, o que significaria dizer se deixarem conduzir pela força do $I d$, isto é, pelo impulso do inconsciente. Isto significaria a liberação absoluta de Eros, que, descontrolado, acabaria conduzindo o ser humano para a sua própria destruição. Neste sentido, o princípio de vida acabaria se confundido com o princípio de morte. Para evitar esse descontrole de Eros, os homens apelaram para as diferentes possibilidades de repressão, formulando, inclusive, um sistema de normas, de leis e de valores que pudesse ser tomado como referência para a justificação dos seus atos repressivos. Ou como se tivesse algo a recorrer para convencer a criança a não destruir seus brinquedos, ou as coisas com que lidasse, visando apenas a satisfação dos seus instintos, como pura gratificação.

Para o estabelecimento dessas normas e dessas leis, criaram-se os mitos e as religiões, para difundirem valores, sustentados por dogmas, tabus e preconceitos. Mas não sendo isto suficiente, instituíram o Estado, bem como a Filosofia e a Ciência como meios de convencimento dos homens para a repressão dos seus instintos básicos, seja evitando a pura e simples manifestação deles, ou canalizando toda sua expressão para outros fins, como por exemplo, a estabilidade das relações sexuais com a instituição do casamento ou a necessidade de trabalhar para a garantia de subsistência e existência no mundo. Sendo, para isso, imprescindível a saúde do corpo e da alma, não teríamos como negar a relevância da

\begin{tabular}{|c|c|c|c|c|}
\cline { 2 - 4 } Q Revista Dialectus & Ano 8 & n. 14 & Janeiro - Julho 2019 & p. 70 - 90 \\
\hline
\end{tabular}


interpretação de mundo pela Filosofia e explicação e controle da natureza sob a orientação científica. Nisto, podemos dizer, fundamenta-se o entendimento de que a repressão, se não é louvável, certamente é indispensável para a continuidade da espécie humana e progresso de suas realizações, configuradas no advento e progresso da civilização. Com outras palavras, não seria possível sem o trabalho e o esforço para o controle dos impulsos vitais próprios do homem. Isto significa dizer, seguindo a interpretação de Marcuse, que os instintos animais forma convertidos em instintos humanos para que se viabilizasse o mundo da cultura à medida em que os homens se orientassem pelas determinações que lhe fossem exteriores. Ou seja: "O homem animal converte-se em ser humano somente através de uma transformação fundamental da sua natureza, afetando não só os anseios instintivos, mas também os 'valores' instintivos - isto é, os princípios que governam a consecução dos anseios" (MARCUSE, 1981, p. 34).

$\mathrm{O}$ advento desses princípios e a sua efetivação nas relações dos homens entre si e com a natureza, não seria possível sem o estabelecimento da dominação de uns homens pelos outros, ficando sua maioria, ou mesmo sua totalidade, sob o comando de um ou de uns poucos, que passaram a governar em nome do interesse de todos, mesmo quando, ao invés disso, governaram em função dos seus próprios interesses. Criou-se assim um sistema de dominação para a administração dos desejos humanos, evitando-se a sua plena gratificação, ao serem canalizados para os fins reconhecidos e aceitos pelo sistema dominante. Com isso se deu a passagem do princípio de prazer, que tem por fim a plena satisfação dos desejos, para o princípio de realidade, que visa o aprimoramento da civilização submetendo os desejos humanos às determinações de uma razão que ordena, deliberando sobre o que deve ou não ser permitido para a manutenção da ordem o do progresso. Assim sendo, esse sistema de dominação, ao eleger valores que pudessem ser requeridos para um bem-estar humano, fez-se também sistema de valores, segundo Marcuse, passando por uma transformação que se configurou da seguinte forma:

1. Da satisfação imediata passou para a satisfação adiada;

2. Do prazer passou para a restrição do prazer;

3. Do júbilo, enquanto atividade lúdica, passou para o esforço, que se tem como trabalho;

4. Da receptividade passou para a produtividade;

5. Da ausência de repressão passou para a segurança.

\begin{tabular}{|l|c|c|c|c|}
\cline { 2 - 4 } & Ano 8 & n. 14 & Janeiro - Julho 2019 & p. $70-90$ \\
\hline
\end{tabular}


Partindo desse entendimento, Marcuse diz que a transformação do sistema de valores culminou, segundo Freud, na transformação do princípio de prazer em princípio de realidade. Assim sendo, a luta do inconsciente, constituída pelos mais remotos processos mentais, inicialmente, dá-se pela obtenção do prazer, mas retrai-se, segundo Freud, como atividade mental para evitar qualquer operação que possa dar origem à dor, enquanto sensação de desprazer. Mas esta atividade mental, como expressão do princípio de prazer, entra em conflito com a realidade natural e humana. Com isso se dá a experiência traumática do indivíduo que passa a compreender a impossibilidade de "uma plena e indolor gratificação de suas necessidades", tornando-se assim uma "experiência de desapontamento". Depois disso, diz Marcuse (1981, p. 34): "um novo princípio de funcionamento mental ganha ascendência". Daí a seguinte reflexão: “O princípio de realidade supera o princípio de prazer: o homem aprende a renunciar ao prazer momentâneo, incerto e destrutivo, substituindo-o pelo prazer adiado, restringido, mas 'garantido"' (Ibidem, p. 35). Isso significa que o prazer, que poderia culminar em destruição por se tratar de um prazer momentâneo, não deixa de ser possível, porque foi apenas adiado e restringido, mas não destruído. Com isso, observa Marcuse, a transformação do princípio de prazer em princípio de realidade é uma conquista, porque é um "ganho duradouro", alcançado pela renúncia e restrição", o que significa dizer, de acordo com Freud, que ele não destrona o princípio de prazer, que é salvaguardado, mas apenas o modificado.

Assim, Freud nos diz, primeiro, que a civilização não seria possível sem a transformação do princípio de prazer em princípio de realidade; segundo, que essa transformação fora uma conquista da humanidade. Por outro lado, deixa entrever a possibilidade de manifestação do princípio de prazer, o que significa que ele continua presente, porém modificado, ou seja, adiado. Portanto, pergunta-se por que a humanidade não avançou em direção à plena libertação dos seus instintos básicos, em meio à cultura previamente firmada pela restrição do prazer como manifestação da repressão necessária ao advento e manutenção da civilização. E próprio Freud afirma que a história da humanidade é a história de sua repressão, ou seja, até hoje, não houve saída à sua plena gratificação.

Acompanhando a lógica da repressão, melhor compreendida a partir da exposição das camadas mentais identificadas pelo Id, o Ego e o Superego, somos levados por Marcuse a nos deparar com a transformação da repressão em mais-repressão. Já não se trata mais da necessidade de repressão como restrição ao prazer como vistas ao que se deve dispor dos princípios vitais para a produção da cultura. Não bastaria o homem ser reprimido sob a

\begin{tabular}{|l|l|l|l|l|}
\hline Qevista Qialectus & Ano 8 & n. 14 & Janeiro - Julho 2019 & p. $70-90$ \\
\hline
\end{tabular}


orientação para o trabalho necessário a essa produção. Fez-se também necessário o trabalho, fonte de acumulação de riqueza por parte de quem detivesse o comando para a exploração.

Compreende-se assim a transição do princípio de prazer para o princípio de realidade considerando-se a luta entre os instintos vitais, representados por Eros, e os instintos de morte, representados por Thanatos. Marcuse chama a atenção para a evolução do pensamento de Freud, quando deixa de pensar Eros apenas como um grupo de instintos sexuais em sua relação com o princípio de autopreservação, que, então, era concebido como um grupo de instintos de ego para pensá-lo a partir das camadas mentais, estando nela o Id como a camada fundamental e mais antiga como domínio do inconsciente, isto é, como domínio dos instintos primários. Ou seja, segundo Freud, o homem estava livre das formas e dos princípios constituintes do indivíduo que, além de consciente de si mesmo, era um ser social. Então, como estaria o Id e quais os seus fins? Responde Marcuse (1981, p. 47): "Não é afetado pelo tempo nem perturbado por contradições; ignora 'valores, bem e mal, moralidade'. Não visa à autopreservação: esforçase unicamente pela satisfação de suas necessidades instintivas, de acordo com o princípio de prazer". Assim sendo, o ego deixa de ser compreendido apenas como princípio de autopreservação, passando a ser concebido como parte do Id convertida em mediador entre o próprio $I d$ e o mundo que lhe é exterior, onde se encontram os valores que nos levam à compreensão do bem e do mal, permitindo-nos assim falar de moralidade, com bem expressam as palavras de Marcuse (Ibidem): "Sob a influência do mundo externo (o meio), uma parte do id, a que está equipada com os órgãos para a recepção e proteção contra os estímulos, desenvolve-se gradualmente até formar o ego. É ‘o mediador' entre o id e o mundo externo”.

O princípio de realidade se firma a partir do momento em que essa mediação entre o Id e o mundo exterior se faz pelo Ego através da introjeção desse mundo representada pelo Superego, compreendido como representação da sociedade no indivíduo. Ou seja: "No curso do desenvolvimento do ego, outra 'entidade' mental surge: o Superego. Tem origem na prolongada dependência da criança de tenra idade, em relação aos pais; a influência parental converte-se no núcleo permanente do superego" (MARCUSE, 1981, p. 48-49). Assim, o Ego, fazendo-se princípio de autopreservação do indivíduo, destrona o princípio de prazer que é por ele convertido em princípio de realidade. E isto significa que é graças à repressão dos instintos sexuais promovida pelo Ego que se estabelece o princípio de realidade. Todavia, a excessiva imposição do Superego, que consiste na imposição das exigências do presente e do pretérito, faz, por sua vez, a transformação da repressão em mais-repressão, que dá origem a excessiva necessidade de trabalho, que passa do que seria necessário para a produção da cultura para o

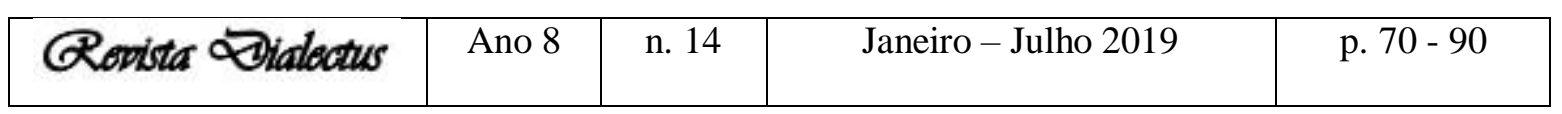


que se faz necessário como acumulação de riqueza. Isto só se faz possível pela exploração fundamentada no princípio de desempenho.

\section{Da carência de dominação ao princípio de desempenho}

Partindo-se do que disse Freud sobre a repressão dos instintos vitais, certificamo-nos de que foi preciso submeter Eros ao princípio de realidade para que se fizesse possível a civilização. Assim compreende-se por que, segundo ele, a história humana começou com a efetiva subjugação dos instintos à dominação do pai primordial, aquele que, na horda primordial, monopolizou o poder e o prazer, impondo aos seus filhos a renúncia, tendo eles que se dedicar ao trabalho, deixando todas as mulheres da horda para o pai, que passou a ser compreendido como arquétipo de dominação. Pois, segundo Freud, o primeiro grupo humano se estabeleceu e se manteve "pelo domínio imposto de um indivíduo sobre os outros". A respeito disto, Marcuse observa o seguinte: "Num dado momento da vida do gênero homem, a vida grupal foi organizada por dominação". Ou seja, "o homem que conseguiu dominar os outros era o pai, quer dizer, o homem que possuía as mulheres desejadas e que, com elas, gerara e conservara vivos os filhos e filhas". Daí se conclui que "O pai monopolizou para si próprio a mulher (o prazer supremo) e subjugou os outros membros da horda ao seu poder" (MARCUSE, 1981, p. 70).

Conforme dissemos acima, de acordo com o entendimento de Freud, essa dominação se fez necessária para que houvesse o advento e o desenvolvimento da civilização. Mas era preciso a ser sentida por todos nós, enquanto filhos desse "pai primordial". Por isso, os filhos se rebelaram contra ele, matando-o e devorando-o. Isto é, fez-se também necessária a morte do pai, para que ele pudesse ressuscitar na forma de sentimento de culpa expressa pelo Superego. Isso explica a luta que, segundo Freud, "é travada e decidida na luta dos instintos - literalmente, uma luta de vida ou morte - em que o soma e a psique, a natureza e a civilização participam" (MARCUSE, 1981, p. 41). Essa luta, por sua vez, expressa a substituição do princípio de prazer pelo princípio de realidade, configurando-se como o "acontecimento traumático no desenvolvimento no homem", visto tanto no âmbito do gênero (filogênese) como no âmbito individual (ontogênese) (Ibidem, p. 36). Esse "acontecimento traumático" diz muito bem o que aconteceu com a transformação do princípio de prazer em princípio de realidade: os desejos do homem, bem como a alteração da realidade que poderia se dar em função desses desejos, deixaram de pertencer ao próprio sujeito. A partir dessa transformação, os desejos do homem e

\begin{tabular}{|c|c|c|c|c|}
\hline Q Rovista Dialectus & Ano 8 & n. 14 & Janeiro - Julho 2019 & p. $70-90$ \\
\hline
\end{tabular}


a alteração da realidade 'passam a ser 'organizados' pela sociedade. E essa 'organização' reprime e transubstancia as suas necessidades instintivas originais". Assim sendo, diz Marcuse (Ibidem, p. 36), "Se a ausência de repressão é o arquétipo de liberdade, então a civilização é a luta contra essa liberdade".

Essa luta da civilização contra a liberdade se faz notar no indivíduo recalcado, que guarda consigo o "sentimento de culpa" em relação à morte do pai primordial, razão pela qual é a ele atribuído um papel decisivo no desenvolvimento da civilização, conforme o entendimento de Freud, que "estabelece uma correlação entre progresso e um crescente sentimento de culpa" (MARCUSE, 1981, p. 83). Assim sendo, para se compreender o desenvolvimento da civilização em seu presente, faz-se necessário conhecer o seu passado. E esse passado se faz conhecido à medida em que somos capazes de relacionar a nossa autorrepressão com o assassinato do pai primordial pelo conluio dos seus filhos, em que se fundamenta o “complexo de Édipo. Com outras palavras, diz Marcuse (Ibidem, p. 83-84):

\begin{abstract}
Recapitulamos sucintamente a pré-história do sentimento de culpa; tem sua "origem no complexo de Édipo e foi contraído quando o pai foi assassinado pelo conluio dos irmãos" [Freud]. Estes satisfizeram seu instinto agressivo; mas o amor que tinham pelo pai causou-lhes remorso, criou-lhes o superego por identificação e, portanto, gerou as "restrições que impediriam a repetição do feito" [Freud]. Subsequientemente, o homem abstém-se do feito; mas, de geração para geração, o impulso agressivo revive, dirigido contra o pai e seus sucessores, e, de geração para geração, a agressão tem de ser inibida de novo [...].
\end{abstract}

Assim, na história da civilização, encontramos as diferentes formas pelas quais se faz a repressão dos instintos vitais como se fosse resposta a uma necessidade de dominação que passou a ser sentida como sentimento de culpa, que se tornara possível graças à ambivalência do amor e ódio: a revolta contra a dominação paternal se dava juntamente com o desejo de ocupar o lugar do pai, o que somente fora alcançado pelo filho mais novo, ao tempo em que o patriarcado fora substituído pelo matriarcado, que afastou a possibilidade de repressão promovida pelo domínio masculino representado pelos irmãos. Estes movidos pelo sentimento de culpa fizeram retornar essa dominação masculina, agora numa outra perspectiva, quando o domínio do pai primordial se fez sentir na dominação de cada um dos filhos. Ou seja, certificamo-nos pelas palavras do próprio Freud (apud MARCUSE, 1981, p. 73) de que "Uma boa parte do poder que ficara devoluto pela morte do pai passou para as mulheres; seguiu-se o período de matriarcado". Todavia, há de se considerar que a liberdade, que se tornara possível com a libertação da mulher, seguiu-se à dominação masculina, isto é, a reafirmação do

\begin{tabular}{|c|c|c|c|c|}
\cline { 2 - 4 } Q Q Onialectus & Ano 8 & n. 14 & Janeiro - Julho 2019 & p. 70 - 90 \\
\hline
\end{tabular}


patriarcado. Isto significa dizer que o matriarcado fora "substituído por uma contra-revolução patriarcal, e esta última é estabilizada mediante a institucionalização da religião" (MARCUSE, 1981, p. 73).

Mas não podemos ignorar a revolução social que ocorreu no período matriarcal. Segundo Freud, depois dessa revolução, a ordem patriarcal foi restaurada, sendo o pai primordial substituído pelos novos pais. No entanto, vale considerar que estes "nunca conseguiram atingir a onipotência do pai primevo. Havia muitos e viviam em comunidades maiores do que fora a horda original; tinham de entender-se mutuamente, conviver e seguir as restrições impostas pelas instituições sociais" (FREUD apud MARCUSE, 1981, p. 74). Essas restrições aqui referidas se fizeram de forma notável pela institucionalização da religião com a substituição das divindades femininas pelos deuses masculinos. A partir daí a recorrência a estes passou a ser constante com vistas a regulamentação da prática sexual que desse sustentação a monogamia como garantia da permanência da propriedade privada sob o domínio de uma elite. Neste sentido, o controle da sexualidade pela religião pôde disciplinar o comportamento no sentido de que o sexo fosse destinado exclusivamente à procriação conforme à necessidade do mundo da produção efetivada pelo trabalho. E isto se fez pela exploração de uns homens pelos outros. Impusera-se a repressão sexual, feita em nome dos deuses masculinos, para garantir a exploração dos trabalhadores que não dispunham dos meios de produção. Assim, a repressão deixou de ser necessária ao desenvolvimento da civilização para ser imprescindível à exploração dos trabalhadores com vistas à geração de mais-valia ao patrão. Neste sentido, a família monogâmica e a propriedade privada foram fundamentais para o controle da sexualidade, como bem observa Marcuse (1981, p. 81):

A família monogâmica, com suas obrigações exigíveis do pai, restringe neste o seu monopólio de prazer; a instituição da propriedade privada transmissível por herança e a universalização do trabalho deram ao filho uma justificada expectativa do seu próprio prazer sancionado, de acordo com o seu desempenho socialmente útil.

Os cristãos, por exemplo, vincularam o sexo à morte e à procriação, porém deixando claro se tratar de pecado toda prática sexual, sobretudo se efetivada fora do casamento. Elevavase assim o pecado do sexo, quando se tratava das relações extraconjugais, bem como das relações pré-conjugais. Neste sentido, faziam-se necessárias a preservação da virgindade e o sexo restrito aos cônjuges, por ser um pecado menor. Esse controle da sexualidade remeteria os instintos sexuais não mais à produção da cultua, de forma que pudesse significar

\begin{tabular}{|c|c|c|c|c|}
\cline { 2 - 4 } & Ano 8 & n. 14 & Janeiro - Julho 2019 & p. $70-90$ \\
\hline
\end{tabular}


desenvolvimento da civilização, mas para a produção de mais-valia, que permitisse o enriquecimento de quem detivesse a dominação por ser dono dos meios de produção. Com isto se firmara a passagem do princípio de realidade ao princípio de desempenho, que tem por base, não a simples repressão sexual, mas a mais-repressão.

Com essa passagem do princípio de realidade ao princípio de desempenho, já não se tem a substituição do princípio de prazer pelo de realidade, mas a transformação do princípio de prazer em princípio de desempenho. Com isto, o monopólio do pai passou a ser a comedida autoridade educacional e econômica. Da mesma forma, a mãe passou a ser o objeto original da luta de Eros e Thanatos, isto é, o objeto da luta entre a vida e a morte. Quanto a isso, Marcuse (1981, p. 81) nos diz o seguinte: "Na horda primordial, a imagem da mulher desejada, a esposaamante do pai, era a imagem de Eros e Thanatos em união imediata, natural". Isto significa que o filho, vendo na mãe o Nirvana pré-natal, desfrutara da ausência de toda necessidade e de todo o desejo. Por isso ela passou a ser o objeto de luta entre Eros e Thanatos, uma vez que ambos passaram a ver nela a possiblidade de alcançar o Nirvana, seja pela plena satisfação do desejo ou pela morte. Mas, atingindo-se o estágio de desenvolvimento da civilização em que o princípio de prazer fora substituído pelo princípio de desempenho, fora dissolvida a identidade entre Eros e Thanatos, de forma que se pode falar agora da separação entre a mãe e a esposa. Neste sentido, pode-se dizer que o amor sensual do filho pela mãe fora inibido, sendo transformado no amor pela esposa e na ternura pela mãe. Posteriormente, o amor e a ternura se reencontrarem na esposa. Assim, diz Marcuse (Ibidem, p. 82): "No presente nível da civilização, dentro do sistema de inibições recompensadas, o pai pode ser superado sem que a ordem instintiva e social sofra violento abalo; agora, sua imagem e sua função perpetuam-se em cada filho - ainda que este o não conheça”. Isto significa, ainda segundo Marcuse (Ibidem), que a dominação não se limita mais às relações pessoais, mas, ao contrário: não só ultrapassou a esfera dessas relações como também "criou as instituições para a satisfação ordeira das necessidades humanas, numa escala crescente". No entanto, segundo ele, "é precisamente o desenvolvimento dessas instituições que está abalando os alicerces estabelecidos da civilização. Seus limites interiores aparecem na recente era industrial”.

Diante disto, irracionalidade do sentimento de culpa é, para Freud, tão racional quanto o é a necessidade de repressão para a própria civilização. Por isso, para se justificar a necessidade dessa repressão, recorre-se à religião que, em nome da necessidade do trabalho para a garantia de sobrevivência e da própria existência humana, canaliza a sexualidade para o empenho que se faz necessário no âmbito da produção econômica submetida à ética do

\begin{tabular}{|c|c|c|c|c|}
\cline { 2 - 4 } Govista Dialectus & Ano 8 & n. 14 & Janeiro - Julho 2019 & p. 70 - 90 \\
\hline
\end{tabular}


capitalismo, como bem observou Max Weber. Pois, ao referir-se a Lutero, diz Weber (2005, p. 76) que "a profissão concreta do indivíduo lhe aparece cada vez mais como uma ordem de Deus para ocupar na vida esta posição concerta que lhe reservou o desígnio divino". Neste sentido, pode-se dizer com Marcuse (1981, p. 85): “A civilização é, acima de tudo, progresso no trabalho - quer dizer, trabalho para o agenciamento e ampliação das necessidades da vida. Esse trabalho realiza-se, normalmente, sem satisfação alguma em si mesmo; para Freud, é desagradável e penoso". Coaduna-se assim a ascese com o trabalho, como mortificação da carne e restrição do sexo à procriação e à sublimação na produção econômica.

A relação que podemos ver nesse incentivo ao trabalho pela via da sublimação pode também ser vista no incentivo à abstinência sexual para se evitar a procriação para a qual o sexo fora destinado, segundo o próprio entendimento cristão. Esse entendimento se apoia na crença de que o dia do Juízo está próximo e, por isso, já não faz sentido procriar. Sendo a procriação a única razão para as relações sexuais, convinha, sim, que se abstivesse da prática sexual. Daí a razão pela qual inúmeras seitas proibiram as relações sexuais, pois, como diz Marilena Chaui (1984, p. 87), “já não havia por que nem para que perpetuar a espécie humana”. Enquanto isso, não seria possível continuar vivo sem as condições matérias de subsistência. Portanto, o trabalho seria imprescindível. Daí uma forte razão para se incentivar o trabalho, que passou a ser o grande purificador da vida suja, conforme o exposto pelos puritanos. Assim sendo, poderse-ia entender o seguinte: "O trabalho é a finalidade da vida e a vida em estado de graças é a vida operosa" (CHAUI, 1984, p. 150).

Assim se consolida o princípio de desempenho sustentado pela mais-repressão. A propósito disto, Anthony Giddens (1996, p. 181), ao referir-se ao pensamento de Marcuse, diz o seguinte: “Toda civilização presume a 'repressão básica' dos caminhos da vida e da morte, mas na sociedade moderna as exigências da disciplina econômica introduzem uma carga de repressão histórica e dispensável”. Ou seja, na sociedade moderna, identificada com o mundo do trabalho que tem a indústria como referência, não se pode ignorar a importância dessa repressão para a afirmação da exploração da mão-de-obra operária. Daí a observação de Giddens: “Ajustando-se ao 'princípio de realidade' de Freud, o indivíduo está, na verdade, respondendo às exigências de uma forma de dominação exploradora" (Ibidem, p. 181-182). Nas palavras do próprio Marcuse (1981, p. 89), está dito: “Supõe-se que os impulsos tanto agressivos como libidinais se satisfazem em trabalhar 'por meio da sublimação', e o caráter 'sadístico' culturalmente benéfico do trabalho tem sido freqüentemente enfatizado".

\begin{tabular}{|c|c|c|c|c|}
\cline { 2 - 4 } & Ano 8 & n. 14 & Janeiro - Julho 2019 & p. $70-90$ \\
\hline
\end{tabular}


Com outras palavras, pode-se dizer que não falta razão para se justificar a necessidade do trabalho, mesmo quando já não mais existe a carência de dominação, própria da hora primitiva, quando a civilização atingiu um grau elevadíssimo de refinamento.

\section{A obsoleta necessidade de dominação e o fim do princípio de desempenho}

Entendendo que já não se faz necessária a dominação para a manutenção da civilização em seu alto estágio de desenvolvimento, vale perguntar pelo que Freud pensou sobre a civilização. Em sua obra $O$ futuro de uma ilusão, ele diz querer significar por civilização humana "tudo aquilo em que a vida humana se elevou acima de sua condição animal", diferindo da vida dos animais (FREUD, 2006, p. 15). E, continuando, diz ainda que ela apresenta ao observador dois aspectos:

Por um lado, inclui todo o conhecimento e capacidade que o homem adquiriu com o fim de controlar as forças da natureza e extrair a riqueza desta para a satisfação das necessidades humanas; por outro, inclui todos os regulamentos necessários para ajustar as relações dos homens uns com os outros e, especialmente, a distribuição da riqueza disponível (Ibidem).

Como se vê, Freud não diz diretamente que a dominação não é mais necessária para a produção da cultura que, para ele, em nada difere da civilização - "desprezo ter que distinguir entre cultura e civilização" - diz ele. Mas Marcuse (1982, p. 23) chama a atenção para o seguinte: "Uma falta de liberdade confortável, suave, razoável e democrática prevalece na civilização industrial desenvolvida, um testemunho do progresso técnico". Ele constata isso ao observar o que está dito em suas palavras: “A tecnologia serve para instituir formas novas, mais eficazes e mais agradáveis de controle social e coesão social” (Ibidem, p. 18). Isto, de alguma forma, confirma o que já havia dito em Eros e Civilização, quando procura saber se existe precondições se pensar em um novo princípio de realidade sob o ponto de vista da qualidade e da não-repressão. Respondendo, confronta "a teoria psicanalítica do homem com algumas tendências históricas básicas", chegando às seguintes conclusões:

1) O próprio progresso da civilização, sob o princípio de desempenho, atingiu um nível de produtividade em que as exigências sociais à energia instintiva a ser consumida em trabalho alienado poderiam ser consideravelmente reduzidas. Por conseqüência, a contínua organização repressiva dos instintos parece ser menos necessitada pela luta pela existência do que pelo interesse em prolongar essa luta, isto é, pelo interesse em dominar. (MARCUSE, 1981, p.123)

2) A Filosofia representativa da civilização ocidental desenvolveu um conceito de razão que contém as características dominantes do princípio de desempenho. Contudo, a mesma

\begin{tabular}{|c|c|c|c|c|}
\cline { 2 - 4 } & Ano 8 & n. 14 & Janeiro - Julho 2019 & p. $70-90$ \\
\hline
\end{tabular}


Filosofia termina na visão de uma forma superior de razão que é a própria negação dessas características nomeadamente, receptividade, contemplação, fruição do prazer. Subentendida na definição do sujeito em termos de uma atividade cada vez mais transcendente e produtiva do ego, está a imagem da redenção do ego: o momento em que venha a repousar de toda a transcendência, num modo de ser que absorveu todo o devir, que está para si mesmo e consigo mesmo em toda alteridade". (Ibidem, p. 124)

Vemos que, primeiro, Marcuse constata que o interesse pelo prolongamento da repressão se vincula ao interesse de dominar, pura e simplesmente, ou seja, não-mais pela carência de dominação com vista à necessidade de produção cultural e desenvolvimento da civilização, mas pelo prazer que possa ser proporcionado pela dominação em si mesma; segundo, a afirmação de um modo de ser que absorveu todo devir sustentando-se num conceito de razão desenvolvido pela Filosofia representativa da civilização, estando nessa razão as características próprias do princípio de desempenho. Ou seja, fora desenvolvido um conceito de razão que serve como instrumento desse princípio de desempenho, ou seja, uma razão que justifica a necessidade de mais-repressão, sem a necessidade de dominação para o desenvolvimento da própria civilização.

A partir disso, Marcuse observa que não seria possível pensar na superação do princípio de desempenho que, para Freud, nada mais era que o próprio princípio de realidade. Mas Marcuse diz que, sendo conforme pensava Freud, não seria possível falar de um novo princípio de realidade: "Se a sexualidade é, em sua própria essência, antissocial e associal, e se a destrutividade é a manifestação de um instinto primário, então a idéia de um princípio de realidade não-repressivo não passaria de especulação ociosa" (MARCUSE, 1981, p. 124). Todavia, há se considerar uma contradição no pensamento de Freud. Ele deixa entrever a possibilidade de libertação humana, fazendo da Psicanálise um instrumento com que combate as neuroses provenientes dessa repressão que ele diz ser necessária ao princípio de realidade, não o distinguindo do princípio de desempenho. Pois eu mesmo observei que fora Freud quem descobriu que a cura da neurose não é devida a outra coisa senão à liberação da natureza e da instintividade do homem” (DIONIZIO NETO, 1988, p. 91). Ou seja, é preciso que se pense na qualidade de vida quando se vive sem-repressão, pois não se pode falar de neurose sem remetêla à repressão sexual. Daí verifica-se, no pensamento do próprio Freud, uma abertura para a libertação, pois "se o processo histórico propender para tornar obsoletas as instituições do princípio de desempenho, tenderá também para tornar obsoleta a organização dos instintos, isto é, para libertar os instintos das restrições e desvios requeridos pelo princípio de desempenho" (MARCUSE, 1981, p. 124), Isto significa haver "a possibilidade real de uma eliminação

\begin{tabular}{|c|c|c|c|c|}
\cline { 2 - 4 } & Ano 8 & n. 14 & Janeiro - Julho 2019 & p. $70-90$ \\
\hline
\end{tabular}


gradual da mais-repressão, pelo que uma crescente área de destrutividade poderia ser então absorvida ou neutralizada pela libido assim fortalecida" (Ibidem).

Mas não se pode ignorar as condições em que se dá a dominação em mundo industrializado, quer dizer, em mundo em que a civilização chegou ao seu mais alto nível de desenvolvimento. Assim já não se fala da dominação do pai primordial nem tampouco da dominação patriarcal pura e simplesmente. A dominação agora se dá no âmbito do sistema que está para além da dominação do Estado. Seguindo por esta linha de entendimento, Marcuse (1981, p. 91) pôde verificar o seguinte:

\footnotetext{
Desde o pai primordial, através do clã fraterno, até o sistema de autoridade institucionalizada que é característico da civilização madura, a dominação torna-se cada vez mais impessoal, objetiva, universal e também cada vez mais racional, eficaz e produtiva. Por fim, sob o domínio do princípio de desempenho plenamente desenvolvido, a subordinação apresenta-se como que efetivada através da divisão social do próprio trabalho (embora a força física e pessoal continue sendo uma instrumentalidade indispensável). A sociedade emerge como um sistema duradouro e em expansão de desempenhos úteis; a hierarquia de funções e relações adquire a forma de razão objetiva: a lei e a ordem identificam-se com a própria vida da sociedade. No mesmo processo, também a repressão é despersonalizada: a restrição e arregimentação do prazer passam agora a ser uma função (e resultado "natural”) da divisão social do trabalho.
}

Assim não podemos ignorar o caráter administrativo da dominação, ao tempo em que desapareceram por trás das instituições as imagens do pai, chefe, patrão, etc. Daí eu observo, a partir do exposto por Marcuse, que "os subordinados são subordinados de outros subordinados. Empregadores e empregados são controlados pela administração de um escritório”. Ou seja: “O responsável pela organização da vida de cada um é o 'sistema', sendo este a soma total das instituições que controlam, satisfaze, determinam a sua necessidade". E com isto se pode afirmar que "a revolta dos indivíduos, hoje, já não é contra o pai, o chefe, o patrão, mas contra as instituições, o sistema como um todo. (DIONIZIO NETO, 1988, p. 91).

Pensando, então, sobre o que significa hoje a necessidade de dominação para que seja canalizada a libido para o trabalho com vista à produção da cultura e, com isto, ocorra o desenvolvimento da civilização, é possível concluir com Marcuse que essa carência de dominação está obsoleta. Tendo se torando obsoleta, já não há mais razão para se continuar com a repressão dos instintos vitais, e muito menos se faz necessária a mais-repressão, que seve de base para o princípio de desempenho. Neste sentido, deveríamos, sim, considerar o necessário fim desse princípio de desempenho, quando a necessidade de dominação se fez obsoleta.

\begin{tabular}{|c|c|c|c|c|}
\cline { 2 - 4 } & Ano 8 & n. 14 & Janeiro - Julho 2019 & p. $70-90$ \\
\hline
\end{tabular}




\section{À guisa de conclusão: a sociedade sem-repressão sob o novo princípio de realidade}

Seria, então, possível pensar numa sociedade sem-repressão, que desse lugar a novo princípio de realidade? Ou já estamos nela? Isto é: já podemos dizer que, tendo se tornado obsoleta a necessidade de dominação, alcançamos a sociedade sem-repressão prevista por Marcuse? José Guilherme Merquior refere-se a esta previsão de Marcuse como utopia que, segundo ele, está situada para além do que ele chama "história viável". Apesar disso, ele diz existir: "é, naturalmente, a sociedade sem repressão. Ela pressupõe a abolição do trabalho e a inauguração de uma sociedade lúdica” (MERQUIOR, 1969, p. 36 - grifo do autor). Ressaltese aqui um equívoco a referência à "abolição do trabalho", pura e simplesmente. Na verdade, Marcuse pensa em abolição do trabalho alienado, ao modo referido por Marx em seus Manuscritos econômico-filosóficos. Todavia, pensando na perspectiva marcusiana, o que está posto entre nós, hoje, pode ser indicativo dessa sociedade lúdica, isto é, sem-repressão.

No início da década de 1970, Carl R. Roger publica Novas formas do amor: o casamento e suas alternativas. Nesta obra, o autor traz para a nossa reflexão um cuidadoso estudo sobre diferentes experiências de casamento ou de novas relações amorosas, que ele acreditava não serem diferentes por volta do ano 2000. No pós-ano 2000, o que dizer dessas experiências: seriam elas indicativo de que a mais-repressão deixou de existir, e contamos agora com a reconciliação dos princípios do prazer e de realidade? Bento Prado Jr., ao discorrer sobre o pensamento de Marcuse, volta-se para esta necessidade de reconciliação, colocando, segundo ele, os princípios de prazer e realidade em novos termos. Assim, diz ele: "O trabalho pacificador da dialética e a idéia de uma civilização não-repressiva que tal trabalho promove não ferem, segundo Marcuse, a vocação mais profunda do pensamento de Freud” (PRADO JR., 1990, p. 271). Ao contrário disto, diz este autor, parece que Marcuse deu o passo final que poderia ter sido dado pelo próprio Freud.

Alvin Toffler (1980, p. 23), no final do século XX, fala-nos da emergência de uma nova civilização: "Uma nova civilização está emergindo em nossas vidas e por toda a parte há cegos tentando suprimi-la". Mas como seria esta civilização? Teria alguma semelhança com o que pensara Marcuse sobre a sociedade sem-repressão? Toffler diz que esta civilização "traz consigo novos estilos de família, modos de trabalhar, amar e viver diferentes; uma nova economia; novos conflitos políticos; e, além de tudo isto, igualmente uma consciência alterada". Logo depois, acrescenta: "Fragmentos desta civilização já existem. Milhões de pessoas já estão sintonizando suas vidas com o ritmo de amanhã. Outros, aterrados diante do futuro, estão

\begin{tabular}{|l|l|l|l|l|}
\cline { 2 - 5 } Q Q Dialectus & Ano 8 & n. 14 & Janeiro - Julho 2019 & p. 70 - 90 \\
\hline
\end{tabular}


empenhados numa fuga inútil para o passado e tentam restaurar o mundo moribundo que lhes deu o ser" (p. Ibidem). Ou seja, com outras palavras, repete o que dissera Carl R. Roger, ao se referir à extensão do que estava acompanhando em relação às novas formas de amar.

Enquanto isso, Jean Baudrillard diz que hoje vivemos "uma espécie de epidemia do valor", ou seja, parece que tudo vale tudo ou que nada vale nada. Isto porque, segundo ele, o momento atual parece ser aquele que sugira depois da orgia. $\mathrm{O}$ que ele quis dizer com isso? Fazendo uso de suas próprias palavras, diz: "Se fosse caracterizar o atual estado de coisas, eu diria que é o da pós-orgia. A orgia é o momento explosivo da modernidade, o da libertação em todos os domínios". Ou seja: "Liberação política, liberação sexual, liberação das forças produtivas, liberação da mulher, da criança, das pulsações inconscientes, liberação da arte". Portanto, a modernidade explodiu como uma orgia total: "Total orgia de real, de racional, de sexual de crítica e de anticrítica, de crescimento e de crise de crescimento" (Baudrillard, 1990, p. 9). Será que estamos a falar de uma sociedade pós-moderna? Esta seria o lugar para o novo princípio de realidade anunciado por Marcuse?

Zigmunt Bauman prefere referir-se à liquidez da sociedade contemporânea. Uma sociedade que não está posta como pós-moderna, mas como modernidade líquida. Isto porque, segundo ele, trata-se de uma sociedade que se caracteriza pela fluidez, o que também a deixa leve. Pois, para ele, "fluidez" ou "liquidez" devem ser consideradas "como metáforas adequadas quando queremos captar a natureza da presente fase, nova de muitas maneiras, na história da modernidade" (BAUMAN, 2017, p. 9). Esta forma de pensar a sociedade contemporânea pode inclusive ser tomada como resposta ao próprio Marcuse, quando diz crer "que estamos diante de uma situação nova na história, porque temos que ser libertados de uma sociedade, rica, poderosa e que funciona relativamente bem..." (MARCUSE apud BAUMAN, 2017 , p. 25).

Seroa possível uma compatibilidade entre a fluidez referida por Bauman com a nãorepressão a que se refere Marcuse. Numa sociedade que se tornasse possível a reconciliação entre os princípios de prazer e de realidade, certamente existiriam para a liberdade sexual. E, neste sentido, trata-se de considerar a condição da sexualidade em meio a essa reconciliação dos princípios: "Sob condições não-repressivas, a sexualidade tende a tornar-se Eros - quer dizer, à auto-sublimação em relações duradouras e expansivas (incluindo relações de trabalho) que servem para intensificar e ampliar a gratificação instintiva” (MARCUSE, 1981, p. 193). Mas o próprio Marcuse diz o seguinte: “como pode a civilização gerar livremente a liberdade,

\begin{tabular}{|c|c|c|c|c|}
\cline { 2 - 4 } & Ano 8 & n. 14 & Janeiro - Julho 2019 & p. $70-90$ \\
\hline
\end{tabular}


quando a não-liberdade se tornou parte integrante da engrenagem mental? E, se assim não for, quem está autorizado a estabelecer e impor os padrões objetivos?” (Ibidem, p. 195).

Em sua obra A ideologia da sociedade industrial, Marcuse, de algum modo reflete sobre o significado da fluidez de uma sociedade em que se tem a dessublimação controlada. Consideradas as condições em que se dão as relações sexuais, a começar pela ambientação da permissividade para a sedução e a conquista, parece ser demarcado pela previsibilidade que nega a plena liberação sexual referida por Baudrillard. Inegavelmente, as pessoas se relacionam de forma leve, que expressa muito bem a fluidez referida por Bauman, mas Marcuse chama a atenção para o fato de que está tudo sob controle, mesmo quando isto ocorre de forma disfarçada, porém, liquidamente presente nos espaços em que se dão as relações. Pois já não se faz necessária a sublimação. Ao contrário, a dessublimação viabiliza a satisfação imediata. Todavia, há de se considerar a liberalização da sexualidade que se dá pela absorção do Princípio da Realidade pelo Princípio do Prazer. Apesar dessa liberalização da sexualidade se fazer "sob formas socialmente construtivas", é inegável a existência de formas repressivas de dessublimação, que "opera como o subproduto dos controles sociais da realidade tecnológica, que amplia a liberdade enquanto intensifica a dominação" (MARCUSE, 1981, p. 82).

Para Marcuse, há, na sociedade contemporânea, um elo entre a dessublimação e a tecnologia. Isto implica "modificação do uso social da energia instintiva" (Ibidem). Com esta modificação, diminui-se a eroticidade ao tempo em que se libera a energia sexual. Ao intensificar a energia sexual, "a realidade tecnológica limita o alcance da sublimação. Reduz também a necessidade de sublimação" (Ibidem, p. 83 - grifo do autor). Isto significa dizer que é cada vez maior o grau de liberdade sexual, como observa o próprio Marcuse (1981, p. 84): "Tem sido com frequência observado que a civilização industrial desenvolvida opera com um maior grau de liberdade sexual - 'opera' no sentido de essa liberdade se tornar um valor marcante e um fator de costumes". E diz mais: "Sem deixar de ser um instrumento de trabalho, o corpo tem permissão para exibir suas características sexuais no mundo de trabalho cotidiano e nas relações de trabalho". Assim sendo, pode-se constatar o seguinte:

As escriturárias e balconistas sensuais, o chefe de seção e o superintendente e atraentes e viris são mercadorias altamente comercializáveis, e a posse de amantes apropriadas - antes uma prerrogativa de reis, príncipes e lordes - facilita a carreira até mesmo de empregados de cargos menos importantes na comunidade comercial. (MARCUSE, 1981, p. 84).

Constata-se, dessa forma, persistência da repressão, mesmo numa sociedade em que as relações humanas se dão no seu modo mais líquido de ser. A mulher, prazer supremo da horda

\begin{tabular}{|c|c|c|c|c|}
\cline { 2 - 4 } Q Devistalectus & Ano 8 & n. 14 & Janeiro - Julho 2019 & p. 70 - 90 \\
\hline
\end{tabular}


primordial, alcançou o seu mais alto grau de emancipação, o que se pode confirmar pelo nível de liberação sexual em que ela se encontra. Mas, como vemos a partir do exposto por Marcuse, trata-se de uma liberação sexual submetida aos condicionamentos sociais, previsivelmente pensados para o controle da dessublimação. Ou seja, ao invés de reprimir o sexo e oferecer as condições para a sublimação, incentiva-se a sexualidade, porém reduzido o caráter erótico das relações. Por assim ser, faz-se a integração entre sexo e trabalho, da mesma forma que se integra o sexo nas relações públicas. Isto facilita a satisfação sexual, porém sob controle. Daí a afirmação de Marcuse (1981, p. 85): "Essa mobilização e administração da libido pode ser a responsável por muitos da submissão voluntária, da ausência de terror, da harmonia preestabelecida entre necessidades individuais e desejos, propósitos e aspirações socialmente necessários". Portanto, se podemos esperar pela superação desse controle a que ainda está submetida a satisfação sexual em uma sociedade em que tudo é fluido, ainda não se pode afirmar que tenha desaparecido, de uma vez por toda, a mais-repressão, que continua sustentando o princípio de desempenho, mesmo com a absorção do princípio de realidade pelo princípio do prazer.

\section{Referências}

BAUDRILLARD, Jean. A transparência do mal; ensaio sobre os fenômenos extremos. Tradução por Estela dos Santos Abreu. Campinas-SP: Papirus, 1990. 188 p. Tradução de: La transparence du mal. Ensai sur les phénomenes extrêmes.

BAUMAN, Zygmunt. Modernidade líquida. Tradução por Plínio Dentzien. Rio de Janeiro, 2017. Tradução de: Liquid Modernity.

CHAUI, Marilena. Repressão sexual: essa nossa (des)conhecida. São Paulo: Brasiliense, 1984.

DIONIZIO NETO, Manoel. A presença do hedonismo e do pragmatismo na visão ética contemporânea. Maceió: Ediculte, 1988. 142 p.

FREUD, Sigmund. O Futuro de uma Ilusão. In: FREUD, Sigmund. O Futuro de uma Ilusão, O mal-estar na civilização e outros trabalhos. Tradução José Octávio de Aguiar Abreu. Rio de Janeiro: Imago, 2006. p. 15-63. (Edição standard brasileira das obras psicológicas completas de Sigmund Freud, v. XXI - 1927-1931).

GIDDENS, Anthony. A transformação da intimidade: sexualidade, amor \& erotismo nas sociedades modernas. Tradução por Magda Lopes. 2a . Reimpressão. São Paulo: UNESP, 1996. 232 p. (Biblioteca Básica). Tradução de: Transformation of intimacy: sexuality, love \& eroticism in modern societies.

\begin{tabular}{|l|c|c|c|c|}
\cline { 2 - 4 } Q Oenistalactus & Ano 8 & n. 14 & Janeiro - Julho 2019 & p. $70-90$ \\
\hline
\end{tabular}


MARCUSE, Herbert. A ideologia da sociedade industrial. Tradução por Giasone Rebuá. 6. ed. Rio de Janeiro: Zahar, 1982. 240 p. (Atualidade). Tradução de: One-Dimensional Man Studies in the Ideology of Advanced Industrial Society.

MARCUSE, Herbert. Eros e civilização: uma interpretação filosófica do pensamento de Freud. Tradução por Álvaro Cabral. 8. ed. Rio de Janeiro: Zahar, 1981. 232 p. (Série Filosofia). Tradução de: Eros and civilization a philosophical inquiry into Freud.

MERQUIOR, José Guilerme. Arte e sociedade em Marcuse, Adorno e Banjamin: ensaio crítico sôbre a escola neohegeliana de Frankfurt. Rio de Janeiro-GB: Tempo Brasileiro, 1969. (Biblioteca Tempo Universitário, 15).

PRADO JR., Bento. Entre o alvo e o objeto do desejo: Marcuse, crítico de Freud. In: NOVAES, Adaulto (Org.). O desejo. São Paulo: Companhia das Letras, 1990. 503 p.

ROGERS, Carl R. Novas formas de amor; o casamento e suas alternativas. Tradução por Octavio Mendes Cajado. 6. ed. Rio de Janeiro: José Olympio, 1984. 240 p. Tradução de: Becoming partners: marriage and its alternatives.

TOFFLER, Alvin. A terceira onda. Tradução por João Távora. 15. ed. Rio de Janeiro: Record, 1980. Tradução de: The third wave.

WEBER, Max. A ética protestante e o "espírito" do capitalismo. Tradução por José Marcos Mariani de Macedo. $3^{\circ}$ reimpressão. São Paulo: Companhia das Letras, 2005.

\begin{tabular}{|c|c|c|c|c|}
\hline Qevista Dialectus & Ano 8 & n. 14 & Janeiro - Julho 2019 & p. $70-90$ \\
\hline
\end{tabular}

